\title{
High expression of CD40 on skin fibroblasts from patients with systemic sclerosis
}

\author{
Jae-Bum Jun • Tae-Hwan Kim • \\ Young-In Na $\cdot$ Dae-Hyun Yoo
}

Published online: 2 September 2007

(C) Springer-Verlag 2007

\section{Erratum to: Rheumatol Int}

\section{DOI 10.1007/s00296-007-0393-7}

The original version of this article unfortunately contained a mistake in the Acknowledgement.

The name of Dr. Keith B. Elkon was spelled incorrectly.

The online version of the original article can be found under doi:10.1007/s00296-007-0393-7.

J.-B. Jun $(\bowtie) \cdot$ T.-H. Kim · D.-H. Yoo

Department of Rheumatology,

The Hospital for Rheumatic Diseases,

Hanyang University, Haengdang-Dong,

Sungdong-Gu, Seoul 133-792, Korea

e-mail: junjb@hanyang.ac.kr

\section{Y.-I. Na}

Institute of Rheumatism, Hanyang University,

Haengdang-Dong, Sungdong-Gu,

Seoul 133-792, Korea 